\title{
La etnografía de performance como herramienta para la investigación en artes escénicas
}

\author{
JPerla Jazmín López Peñuelas \\ perla.lopez@capomo.uson.mx \\ Diana Brenscheidt genannt Jost \\ diana.brenscheidt@unison.mx \\ Universidad de Sonora
}

\section{Introducción}

El propósito de este trabajo es discutir algunas alternativas para la investigación de y en las artes escénicas, cuyo enfoque nos permita reflexionar sobre el papel del artista escénico en el proceso creativo y en relación con el entorno y contexto en que dicho proceso tiene lugar. Se fundamenta en un diálogo entre los trabajos sobre etnografía de perfomance de Dwight Conquergood y las reflexiones sobre performance y etnografía de Diana Taylor.

Se analizarán aspectos concernientes al diálogo entre teoría y práctica que estos enfoques ofrecen al otorgar un lugar primordial a lo vulnerable y cambiante del cuerpo, a su memoria y sensibilidad, frente a los acercamientos abstractos y autoritarios. También, abordaremos las aportaciones que los artistas escénicos pueden hacer al ámbito de la investigación a través de sus itinerarios corporales, para después referirnos de manera particular a los estudiantes de artes escénicas y cómo estos podrían vincularse con el mundo de la investigación académica a partir de las herramientas, habilidades y conocimientos adquiridos durante su formación de ejecutantes o creadores escénicos.

\section{Los estudios de performance}

Los estudios de performance se articulan a mediados del siglo $\mathrm{XX}$ en una lucha por poner en relieve el conocimiento práctico, encarnado y popular que hasta entonces ocupaba un lugar secundario frente al otro dominio de conocimiento, el oficial, objetivo y abstracto con sus correspondientes enfoques textual y culto. Los estudios del performance se autodefinían como radicales, puesto que, al poner la acción en el centro, cortaban la raíz de cómo el conocimiento es organizado en la academia.

Los estudios de performance parten del conocimiento teatral y del performance art para trasladarlo a múltiples facetas de la vida, proponiendo el estudio de los diferentes eventos vistos "como performance" (Schechner, 2012). Esto es, considerando a la conducta humana como algo reiterado y ensayado, de manera que, a través de sus acciones, los hombres y mujeres están siempre representándose a sí mismos y asumiendo distintos roles (llámense teatrales, profesionales o de la vida cotidiana). Esto quiere decir que cualquier evento, como una celebración familiar, un discurso político, una representación escénica, un proceso creativo o cualquier comportamiento profesional, puede ser estudiado "como performance", es decir como una conducta ensayada y reiterada dentro de un contexto cultural y social.

Los Performance Studies de la Tisch School of the Arts de la Universidad de Nueva York, surgen como respuesta a la necesidad de una disciplina que organizara este paradigma "como performance". Para Richard Schechner, uno de los fundadores de esta disciplina, los estudios de performance, más allá de considerar los aspectos performativos de la cultura desde las ciencias 
humanas y sociales, ponen en relieve un conocimiento generado desde el teatro y el performance art como manera de analizar y accionar ante las problemáticas sociales. Y no deja de considerar que a partir de otras disciplinas como la danza se generen otros métodos y herramientas de investigación para el estudio del performance social.

A partir de estos planteamientos se han generado líneas de investigación que abordan el performance como teoría y como método, que se relacionan y alimentan con otros enfoques como el performance feminista y de género, las representaciones de turismo y museos, performance de la vida cotidiana, performance de vanguardia, estudios de danza y entretenimientos populares. En relación con la danza, a partir de los años 90's se desarrollan en Estados Unidos algunas vertientes: etnología de la danza, estudios culturales en danza, etnocoreología, estudios de performance, antropología de la danza, etc. Antecedentes notables en Latinoamérica serían los trabajos de Citro (2012), antropóloga y bailarina argentina, quien se ha dedicado a investigar lo relacionado a la antropología del cuerpo y el performance.

Pero, ¿qué implica estudiar un evento "como performance"? La siguiente cita a Richard Schechner nos permite dilucidar como tanto en el mundo de la investigación, como en el arte hemos caminado por el sendero que acorta la distancia entre hecho escénico y vida real, entre arte e investigación, entre arte y acción social.

Aceptar lo performativo como categoría teórica y como hecho de conducta hace cada vez más difícil sostener la distinción entre apariencias y hechos, superficies y profundidades, ilusiones y sustancias. Las apariencias son realidades. Y las realidades son también lo que está detrás de las apariencias. La noción de "verdad” como "natural” o “fija” se vuelve dudosa. La realidad social y hasta física se comprende hasta sus múltiples profundidades. Este profundo relativismo... perturba a muchos que desean un apoyo más firme, más establecido, más “universal” de valores, de prácticas sociales correctas e identidades personales. Los estudios de performance trabajan con y a través de la mirada de puntos de contacto y de yuxtaposiciones, tensiones y lugares sueltos, separando y conectando seres humanos y telas de significación que nuestra especie sigue tejiendo (Schechner, 2000, pp. 19-20).

Este desmoronamiento de las fronteras, el moverse en el límite, y la no-universalidad de los valores y las jerarquías, en teoría, nos permitiría acceder a un trabajo que desmitifica al artista, en su concepción de genio

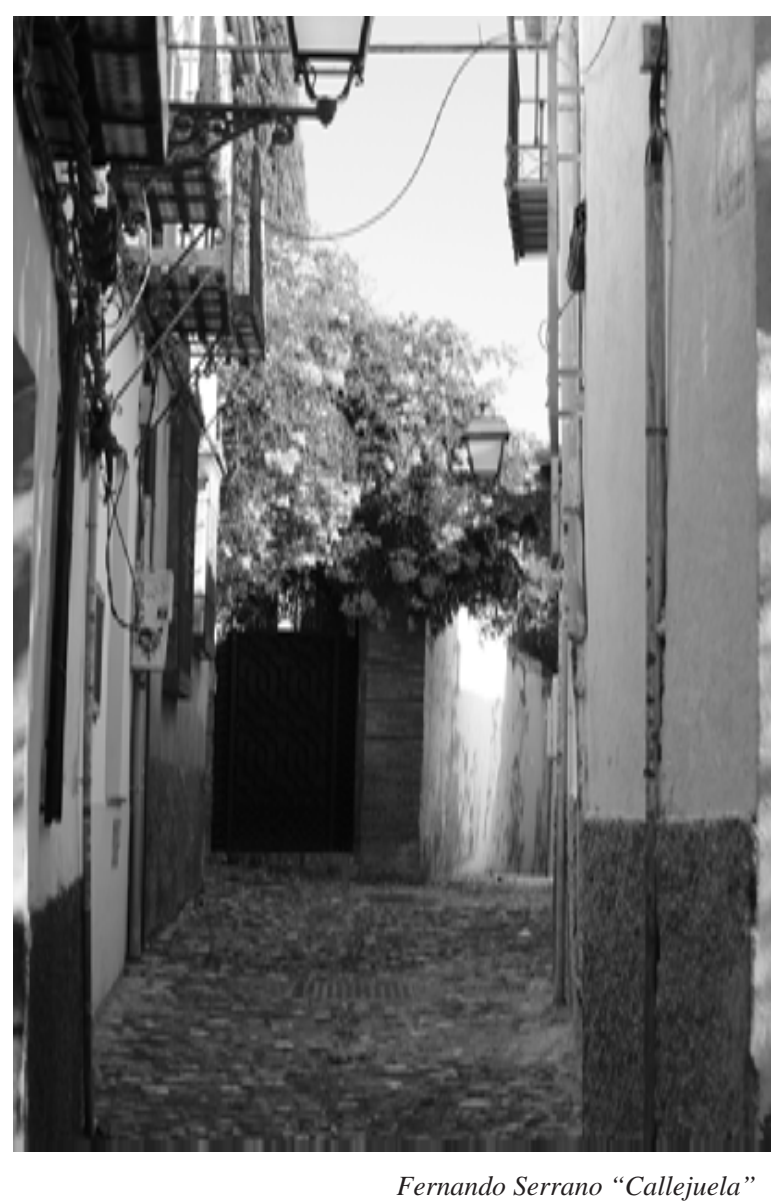


romántico o autor único, en el caso de las artes escénicas. A la vez que podría empoderar al intérprete dentro de la red de producción y socialización del arte, al ubicarlo como un actor entre otros, dentro de un contexto social e inmerso en una cultura. Todo esto a fuerza de poner en relieve las percepciones y usos del cuerpo, así como sus influencias, creencias, sometimientos y liberaciones.

Algunas implicaciones de estudiar "como performance”, serían las siguientes:

- Analizar nuestra performance escénica y profesional como performance social y cultural.

- Integrar las consideraciones culturales que socialmente son compartidas - o que se encuentran en pugna - como parte constitutiva del performance.

- Describir y comprender qué hacen los artistas escénicos (en términos realizativos/performativos) y cómo lo hacen (en términos performáticos/ al nivel de las palabras y las acciones). Esto abarcaría todos los eventos y escenas de la vida en grupos plausibles de ser analizados "como performance”.

Lo anterior puede considerarse tanto a la luz de una indagación individual, como de manera colectiva o visto como una confluencia que puede ofrecer diversas lecturas del proceso creativo y de los aspectos sociales y culturales que la creación artística genera, absorbe y transforma.

Los artistas tienen aquí la posibilidad de una investigación individual que indaga alrededor de los propios procesos creativos y de la propia corporalidad. Y también la posibilidad de la construcción colectiva de sentido, a partir de la cual se pueden generar diversas lecturas de un proceso creativo o la valorización en colectivo de un proceso o una obra.

\section{Etnografía del performance}

Según Aguirre, la etnografía tradicional entendida como el estudio descriptivo de la cultura de una comunidad, o de alguno de sus aspectos fundamentales, bajo la perspectiva de una comprensión global de la misma (como se cita en Sandin, 2000), ha tenido múltiples aplicaciones en el arte profesional y en el entorno educativo. Resultado de ello son historias biográficas y profesionales o análisis de roles de individuos; las microetnografías de pequeños grupos de trabajo; y estudios de grupos sociales abstraídos como si fueran pequeñas sociedades o culturas.

A mediados de siglo XX surgió una corriente denominada etnografía crítica, la cual se constituyó como parte de una rebelión política en contra de las posiciones positivistas. Considerando que la cultura no está ahí fuera, esperando a ser descubierta, la etnografía crítica puso de relieve el carácter performativo y vivido de la cultura, específicamente de las culturas orales.

Los partidarios de la etnografía crítica estimaban como inevitable la participación del investigador y su influencia en la comunidad o grupo estudiado a través de sus textos, su performance y sus construcciones. La etnografía del performance viene a formar parte de estas tendencias críticas de la etnografía que revolucionaron - más adelante veremos por qué - la producción del conocimiento a nivel académico y han cobrado hoy en día, mayor importancia.

La etnografía de performance tiene su principal antecedente en Conquergood (2013), quien buscaba una alternativa a la etnografía tradicional. Sus principales preguntas eran: ¿cómo los sujetos estudiados le dan sentido a su vida? y ¿cómo resisten a la opresión? Se dedicó a formular una perspectiva de la etnografía que diera cuenta de cómo sus informantes representan 
sus identidades y de cómo estos performances hablan y actúan en y contra las estructuras de poder. El trabajo etnográfico fue enmarcado como un estudio de los performances de la vida diaria, dando cabida, en el ámbito de la investigación etnográfica, a las acciones humanas en los lugares comunes, a las acciones cotidianas y al estudio del comportamiento humano desde el gesto, el cuerpo y sus inconsistencias, y no sólo en lo que respecta a las ideologías y estructuras de poder reconocidas.

Su trabajo se proponía relacionar tres aspectos fundamentales: la creatividad, la crítica y la responsabilidad ciudadana (Conquergood, 2013, p. 43). Lo que implica esta perspectiva para el estudio del performance, es ver el proceso creativo, por un lado, como lugar de interacción, construcción, trasmisión y resistencia cultural. Y, por otro lado, como una fuente de conocimiento y formación a través de la exploración del conflicto cultural en el proceso.

Conquergood (2013), inspirado en el trabajo de Frederick Douglass My Bondage and My Freedom, cuyo original se publicó en 1855, realiza una serie de formulaciones que describen una escena antropológica totalmente distinta a la dominante en su tiempo. Observa en el trabajo de Douglass algunas características que se anticipaban a lo que ahora conocemos como etnografía de performance (pp. 37-38):

- La solidaridad con la gente, en lugar de la separación de la gente.

- La búsqueda de proximidad como punto epistemológico de partida.

- La cadena de acción-sentimiento-comprensión-conocimiento.

- Las estructuras de sentimientos y emociones antepuestas al control cognitivo,

Propuso también algunas líneas de actividad y análisis en las que podemos considerar la etnografía del performance. Estas serían:

- Como un trabajo de imaginación. Esto es, en la construcción de un objeto de estudio.

- Como una práctica de investigación, al considerarse como modelo y método.

- Y cómo una táctica de intervención, es decir, un espacio alternativo para el debate, la reflexión y la acción (Conquergood, 2013 p. 38).

La filósofa y teórica social Donna Haraway contrapone la mirada directa y vulnerable desde el cuerpo a la mirada abstracta y autoritaria de la etnografía tradicional. (citado en Conquergood, 2013, p. 33). Esto implica, que el conocimiento que antes se consideraba subordinado por no ser explícito y textual ahora es puesto en el centro de la indagación.

Cómo ejemplos de esta revolución política a través de la investigación etnográfica, los estudios de performance y el performance art podemos mencionar: el reconocimiento del conocimiento práctico de la danza, frente a los trabajos de investigación teóricos sobre danza realizados desde la historia del arte; o la reevaluación del arte del actor frente a los autores de la literatura dramática; o el reconocimiento al coreógrafo-autor-director de la puesta en escena frente a la subordinación y explotación del intérprete, cuyo trabajo se consideraba de menos valor

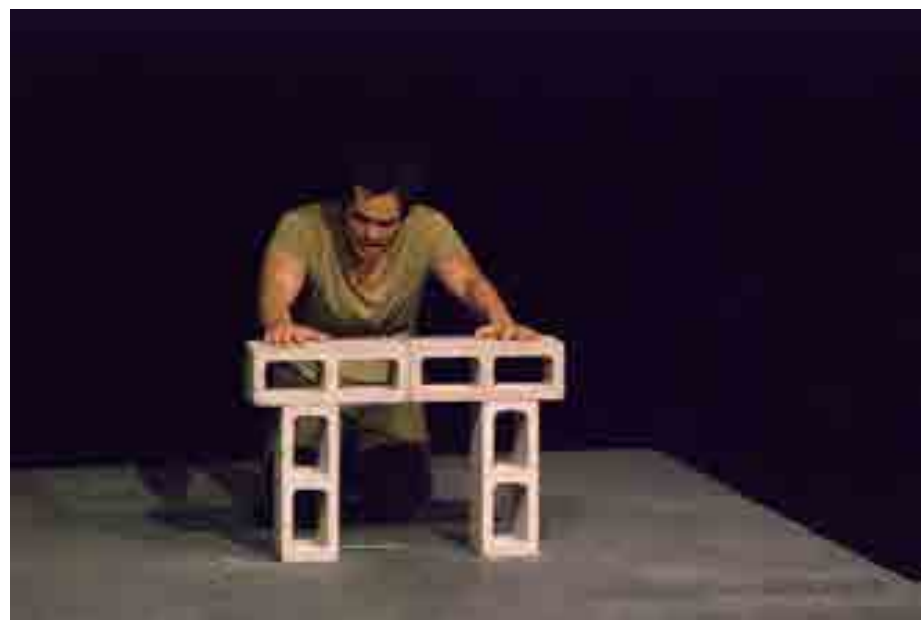

Ana Isabel Campillo 
por ser menos intelectual o de menor jerarquía, y resultado de ello ha sido la creciente utilización de términos como creador escénico o performer; y por último, en el ámbito de la investigación, implicaría que aspectos de la expresión corporal como las entonaciones, silencios, tensiones corporales, gestos faciales, y en general, la experiencia y el acercamiento corporal del investigador a sus informantes, sean considerados como actos e indicios que importan al trabajo de investigación y que desestabilizan las estructuras conocidas, proporcionándonos aproximaciones distintas a los eventos estudiados, en este caso, al arte escénico.

Hasta aquí y bajo las anteriores consideraciones, se puede decir que la etnografía del performance como la planteamos a partir del trabajo de Conquergood, se fundamenta en los aspectos corporales y performativos de los eventos estudiados dentro de un marco espacio-temporal definido de confluencia e integración llamado performance social o cultural. Y hemos destacado la aproximación por la vía corporal a esta performance socio-cultural.

\section{El artista escénico como investigador en la etnografía de performance}

Ahora, llevaremos las ideas expuestas anteriormente a nuestro campo de estudio, el proceso creativo artístico. El arte escénico y el trabajo en grupo de los artistas escénicos como performance socio-cultural, tiene un carácter fluido e indeterminado donde las estructuras son transformables y transformadas (Bianciotti y Ortecho, 2013, p. 123). Pero, ¿cómo son transformadas? ¿y qué actores o fuerzas constituyen este proceso de transformación? Para responder a estas interrogantes - desde la perspectiva de la etnografía de performance - será necesario partir de la idea de que yo como bailarín, actor o performer tengo la capacidad de influir y modificar el proceso y mi entorno, ya que no me encuentro dentro de una estructura cerrada.

De esta manera, el proceso de investigación tendría que partir de la flexibilidad del proceso creativo artístico, sus incongruencias e incoherencias. $\mathrm{Y}$ esto, necesariamente, nos demanda sumar a la cognición y la racionalidad (elementos centrales para la ciencia moderna), la volición y el afecto (Bianciotti y Ortecho, 2013).

Metodológicamente, todos estos aspectos de la vida grupal se analizarían en diferentes estadios del proceso creativo que pueden o no tener un orden cronológico, así como también pueden yuxtaponerse y desplazarse uno al otro, siguiendo la propia lógica del proceso creativo. Al seguir la lógica del sueño y al aspecto lúdico del proceso, este espacio alternativo para el estudio de los aspectos performativos de la cultura, impli-

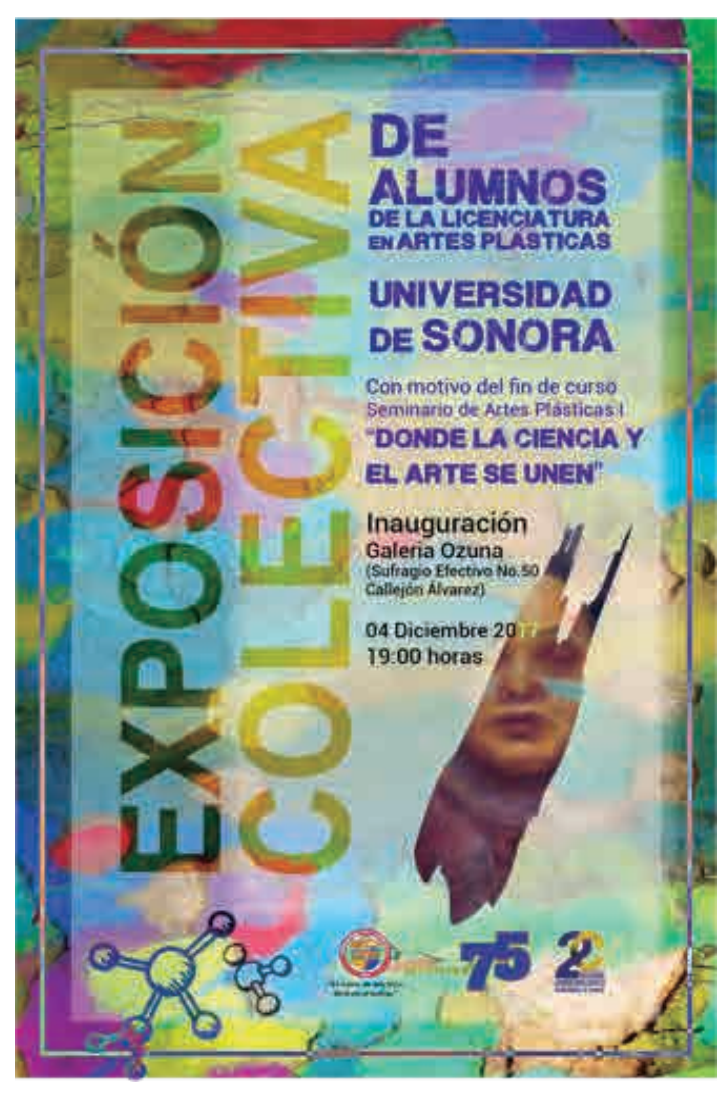

Exposición Colectiva 
caría necesariamente la conexión con una gran diversidad de aspectos de la vida en sociedad, y por lo tanto, un importante intercambio entre disciplinas: historia, estudios culturales, antropología, artes, etc. Y más aún, una visión de tendencia holística de la investigación.

Regresando a los planteamientos de Conquergood (2013), en la etnografía del performance - como en la danza -, la corporalidad del investigador es el principal referente para la investigación, de manera que el rigor de la investigación y la autoridad disciplinaria refieren a los siguientes criterios:

- La duración de la investigación.

- La profundidad de la investigación y grado de compromiso del investigador.

- Los riesgos corporales, físicos y emocionales tomados para la comprensión de la performance cultural.

Resulta curioso que los criterios anteriores no serían distintos de los considerados en el ámbito de las artes escénicas para evaluar la investigación creativa o la efectividad de un artista en escena.

La etnografía del performance exige del investigador la capacidad para identificar y atender tensiones corporales, entonaciones, silencios, gestos y omisiones, los cuales serían a la vez el objeto y el medio para llegar a él. (Conquergood 2013, p. 33) Los artistas escénicos tendríamos mucho que aportar en este aspecto. A través de años de entrenamiento y experimentación, los actores, bailarines y directores de escena, desarrollan - entre otras facetas del cuerpo escénico - métodos, estrategias y habilidades para manejar tensiones, liberar nudos, pensamientos, escudriñar en el deseo y la intención. Los artistas desarrollamos una visión crítica del mundo y a menudo, buscamos generar acciones que impacten nuestro entorno social y resistan a las estructuras dominantes u opresoras.

\section{El itinerario}

La investigación encarnada implica varios niveles de análisis, desde la identificación de fuerzas globales o niveles macro, como también la manera en que estas ideas o marcos de referencia son aplicados y accionados de manera individual. ¿Cómo podemos organizar estas conexiones? Porque al final de cuentas, todos organizamos. De otra manera, el trabajo de investigación y artístico sería impensable e impresentable. Y esta es una de las diferencias entre el artista y el artista-investigador que organiza el proceso de manera en que pueda generar algún tipo de conocimiento comunicable y replicable. Los artistas no nos dejarán mentir, todos aseveran que tenemos nuestro propio método, una forma de hacer distinta del saber científico. Mediante la actividad investigadora, este itinerario puede dialogar y enriquecerse de otras áreas del saber. Y al mismo tiempo puede cruzarse y enriquecer otros itinerarios. Las posibilidades son infinitas, tanto como las que se tienen en frente al iniciar un proceso creativo artístico. Pero hay que resaltar algunas diferencias, porque para completar y acotar el trabajo académico tendríamos que enfocarnos solo en algunos puntos de vista. Es decir, a partir del universo de la creación artística responder determinadas preguntas. En este tipo de estudios se proponen los itinerarios por encima de los lugares prescritos. Un itinerario, para el antropólogo Augé (1996), implica un arranque o punto de salida, un viaje y un retorno. Durante este itinerario, el investigador parte entonces de una configuración inicial y una vista global del objeto de estudio para después formularse preguntas más específicas que le ayuden expandir o refinar su búsqueda. 
Tal como todo proceso de creación artística, el viaje etnográfico del cuerpo implica un estado inicial, un encuentro con otros cuerpos, personas, obras, grupos sociales, y un posterior reconocimiento del aprendizaje, de un nuevo estado, de aquello que en el marco de los estudios de performance Schechner (2012) llamaría "reconocimiento de las repercusiones". En este itinerario, el investigador-etnógrafo-artista, se aventura a la reflexión de su propio rol, sus acciones, y su influencia en el proceso que investiga, así como la forma en que el proceso le transforma y le da un lugar entre los demás actores. Dado que el cuerpo es inaprehensible y es lugar de disidencia, cualquier itinerario de acción siempre puede tener bases inesperadas. Y como ya mencionamos, el proceso puede tener múltiples lecturas, lo que no implica necesariamente imprecisión o informalidad. Retomando a Conquergood (2013), el reto del artista-investigador aquí

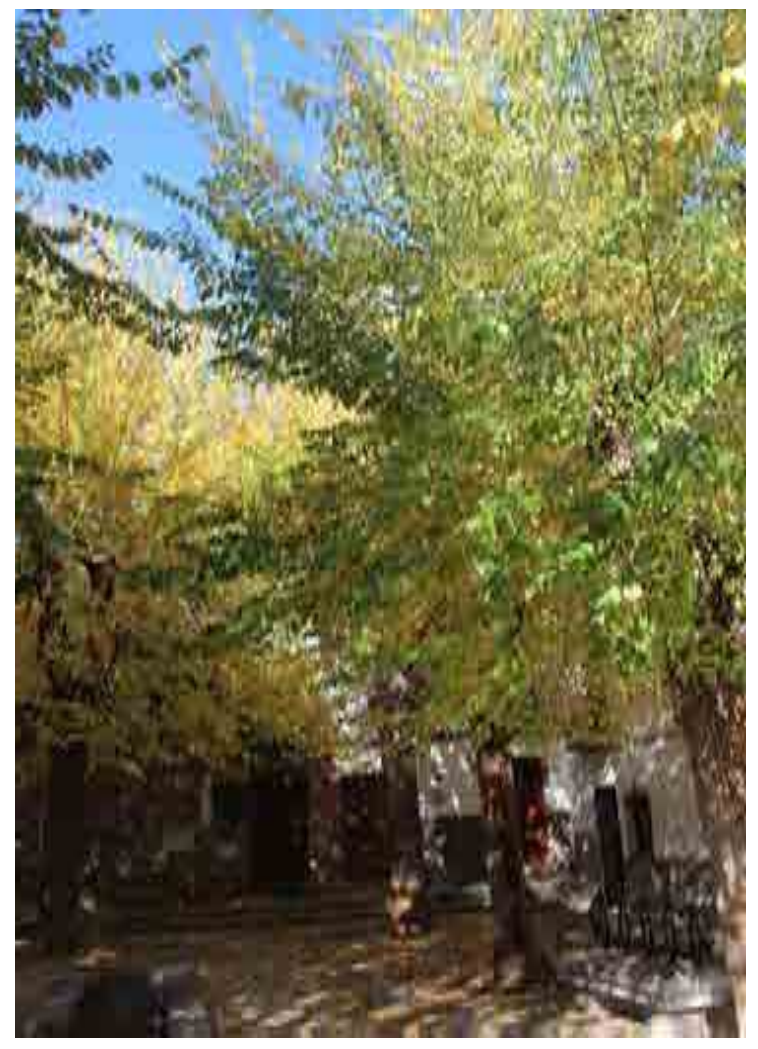

"Impresión en Granada” Fernando Serrano es de aproximación y profundidad.

El análisis en detalle y centrado en un caso específico permite encontrar tanto semejanzas como diferencias entre los diferentes actores que un análisis en superficie evitaría. Recordando que algunas semejanzas pueden ser irrelevantes para nuestros intereses. O que muchas veces dichas semejanzas pueden ser neutralizadas por diferencias que resultan más importantes.

Se propone aquí una base epistemológica muy específica. Como ya mencionamos, la prevalencia de la proximidad sobre la objetividad. Así como una atención a diversas estructuras sensibles, de interacción y convivencia que se entrecruzan en el proceso creativo. Lo que resulta de ello es lo que Geertz (1996), ya defendía alrededor del trabajo etnográfico, un "remolino de conexiones inconstantes”. Un cuerpo a cuerpo que acumula y erosiona sistemas de alianza cambiantes a partir de lealtades interpersonales.

Esta red no puede lograrse sin la conciencia inicial de que una vez terminado el performance y llegado el momento de transcribir, ordenar y socializar la información, estas transcripciones no serán inocentes, sino que tendrán implicaciones políticas. Podemos decir que la mejor y única forma de socializarlo es través de otro performance, y esto sería otro soporte válido para socializar la investigación, pero no necesariamente más fiel que el soporte escrito o audiovisual. Porque que el cuerpo continúa con sus interminables evoluciones, también tendríamos que admitir que el performance ya no nos dice mucho de lo que en efecto sucedió durante el proceso creativo. Ni sabemos a ciencia cierta que queda del performance original, en sus posteriores representaciones.

Entonces, ¿de qué clase de itinerario estamos hablando? Como el artista, el investi- 
gador se hace una pregunta o motivo de partida. Ubica matrices y generalidades, para después movernos en saltos y de manera fragmentaria en lo que ulteriormente constituirá una red de asociaciones y conexiones. La etnografía de performance sería una alternativa para la purificación y organización de observaciones crudas, alrededor de temas y preguntas específicas, partiendo de la experiencia y conocimiento corporal.

Lo que aportamos los artistas a esta etnografía del performance, es una fundamentación en la investigación corporal-escénica. Y lo que ganamos como artistas o lo que nos devolvería la etnografía de performance es el entendimiento de nuestro performance como un tipo de acción social.

Se discute mucho sobre el hecho de que el artista sea incapaz de tomar distancia de sí mismo para elaborar un trabajo de investigación, distancia que, ya hemos visto, bajo la perspectiva de la etnografía del performance resulta innecesaria y más aún, obstaculiza el entendimiento crítico de los eventos o grupos estudiados. La tarea del investigador implicaría la exploración y observación en detalle del evento estudiado, realizar estas observaciones a partir de diferentes consideraciones teóricas y creativas, confrontar estos hallazgos con otras áreas del conocimiento, y además, establecer vínculos con aspectos socio-culturales de la vida del artista. Todo esto implica, necesariamente, tomar cierta distancia de la experiencia en sí para explorar el terreno de las elaboraciones teóricas o de documentación. Es decir, extendemos nuestros horizontes a terrenos distintos de la creación lúdica y el arte por el arte.

Nos lleva a realizar la reflexión del propio rol a través de una visión crítica que no descansa en juicios de valor sobre la obra o sobre los aspectos estéticos de manera aisla- da, sino que reflexiona alrededor de los modos de relación, de las enseñanzas de vida y de lo que al final del proceso ha cambiado en las personas, lo que se ha incorporado como un saber corporal en el artista-investigador.

Herramientas de los artistas y estudiantes de artes escénicas para el abordaje de la etnografía del performance

Retomaremos para ello el propósito principal de estas indagaciones: encontrar alternativas para la investigación de y en las artes cuyo enfoque nos lleve a reflexionar sobre el papel del artista escénico tanto dentro del proceso creativo como en relación con su entorno y el contexto en que el proceso se lleva a cabo. Y que al mismo tiempo establezca un puente saludable y de cooperación entre el ámbito de la investigación y el

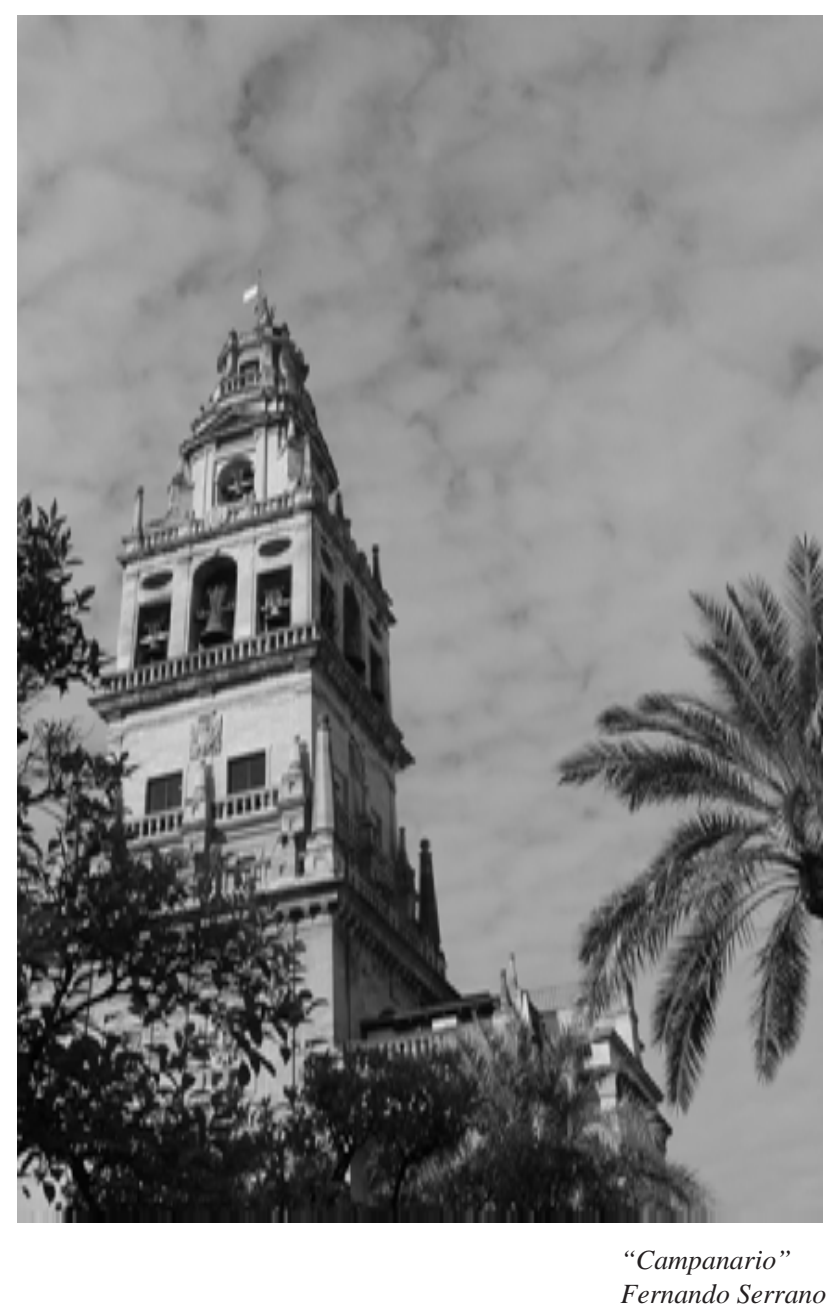


de la creación artística.

Para ello nos hemos apoyado en una base metodológica que pone el acento en el saber corporal, lo sensible y expresivo de las manifestaciones artísticas, así como la noción del proceso creativo como performance cultural que se reconstruye y actualiza con cada representación.

¿Con qué contamos los ejecutantes, creadores escénicos, performers para acercarnos a una alternativa de investigación como la que aquí planteamos? La respuesta es con todo. Como ejemplo vayamos al programa de Licenciatura en Artes Escénicas de la Universidad de Sonora. Los estudiantes de Artes Escénicas se especializan en una de los principales instrumentos de registro etnográfico, las bitácoras. Algunas de formato libre y otras más estructuradas, pero todas enseñan al estudiante a documentar

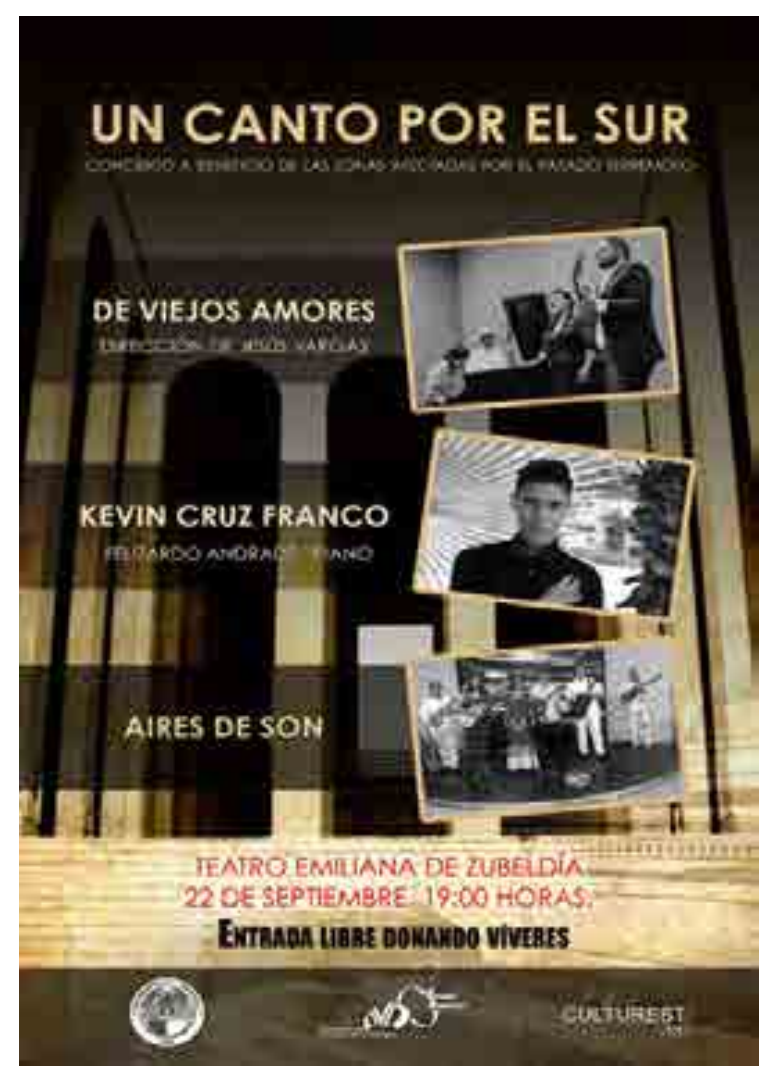

Un canto por el sur diferentes aspectos de su propia performance en la especificidad de un ámbito socio-cultural y performativo (al interior del salón de clase, en los procesos de creación y aún, en su vida personal y cotidiana). La bitácora, además de registrar observaciones acerca de los demás participantes, es un instrumento indispensable para la reflexión del artista y el investigador. Puesto que nos enfrenta al final del día con nuestras propias decisiones, acciones y pensamientos.

Los artistas escénicos dedican años al estudio del comportamiento corporal-humano. Y como los estudios de performance lo han considerado ya, a la identificación de actores sociales, acciones y gestos. Con gran sensibilidad nos abocamos también al estudio de relaciones temporales y espaciales. Todos estos son elementos indispensables para llevar a cabo una investigación como la que aquí planteamos. No sería necesario para mi remplazar los indispensables perfiles de ejecutante o creador escénico para que los estudiantes que se interesen por el ámbito de la investigación puedan incursionar en este campo.

Los procesos mnemotécnicos necesarios para este tipo de investigación se enriquecen y complementan con la experiencia del artista escénico. Las grabaciones audiovisuales, por ejemplo, no constituyen en sí el soporte fidedigno del trabajo etnográfico, sino que fungen como un instrumento de apoyo para el proceso mnemotécnico del investigador y que mediante un tratamiento de edición pueden servir posteriormente para ilustrar sus argumentos. Sin embargo, no pueden dar un testimonio completo del proceso estudiado.

Es la sensibilidad del artista, su experiencia, memoria kinestésica y emocional lo que realmente puede aportar elementos 
significativos para la comprensión del performance en detalle y lo que nos puede dar cuenta de cómo el artista negocia desde su cuerpo sus acciones, significaciones, poéticas, resistencias y fabulaciones.

\section{Comentarios finales}

A manera de resumen de las ideas anteriormente expuestas resaltaré que la etnografía de performance puede ser un método idóneo para la investigación de y en las artes escénicas. Donde la labor del artista sea vista no solo desde sus aspectos técnicos y estéticos sino como un tipo de acción social y alternativa crítica. Es decir, considerando las interpretaciones, pero también las reglas de interpretación de cada uno, las relaciones interpersonales y la forma en que se negocian las estructuras de poder e ideologías dominantes. Esto implicaría interesarnos en aspectos socio-culturales de la vida del artista en conjunto con el estudio de sus acciones y comportamiento al interior del proceso creativo.

La etnografía del performance sería un enfoque de investigación que considera la sensibilidad corporal, la memoria corporal y su repertorio de acciones como ineludible fuente de conocimiento. De esta manera, los artistas escénicos pueden tomar estas herramientas y bases epistemológicas para enriquecer su labor artística mediante la retroalimentación con otras áreas del saber. Al tiempo que socializan su saber corporal, dialogan con otros itinerarios de investigación y los enriquecen mediante su acción-investigación humana relativa al cuerpo.

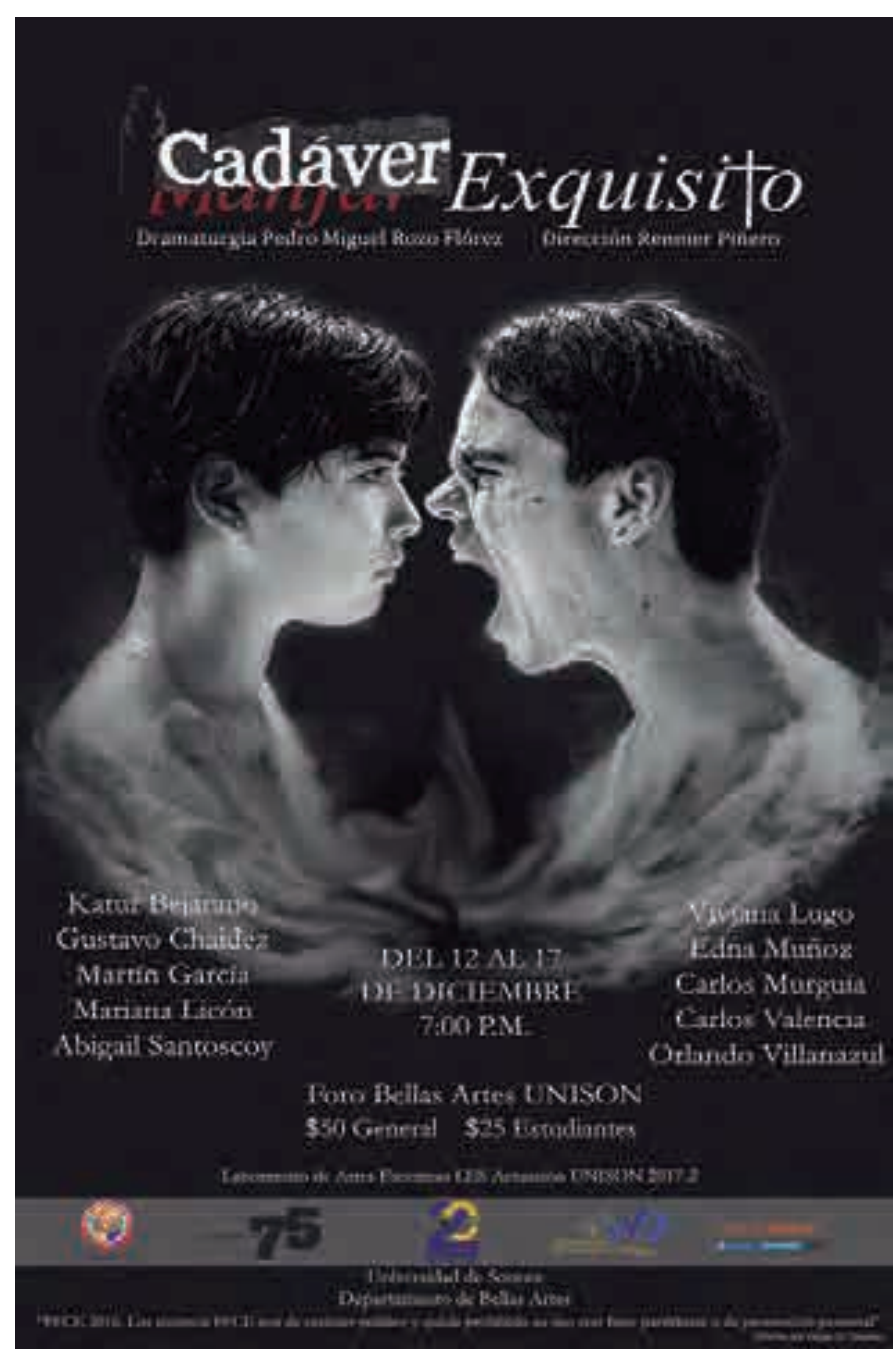

Cadaver Exquisito 


\section{Bibliografía}

Augé, M. (1996). El sentido de los otros. Buenos Aires; Barcelona: Paidós.

Bianciotti, M., y Ortecho, M. (julio-diciembre de 2013). La noción de performance y su potencialidad epistemológica en el hacer científico social contemporáneo. Tabula Rasa(19), 119-137.

Cardona, P. (2012). La poética de la enseñanza. Una experiencia. México D.F:: INBA-CENIDI.

Citro, S., y Patrici, A. (2012). Cuerpos en movimiento. Antropología de y desde las danzas. Buenos Aires: Editorial Biblios.

Conquergood, D. (2013). Cultural struggles. Performance, ethnography, praxis. Ann Arbor: University of Michigan.

Geertz, C. (1996). Tras los hechos. Buenos Aires: Paidós.

Schechner, R. (2000). Performance: teoría y prácticas interculturales. Buenos Aires: Libros del Rojas.

Schechner, R. (2012). Estudios de la representación. México: Fondo de Cultura Económica.

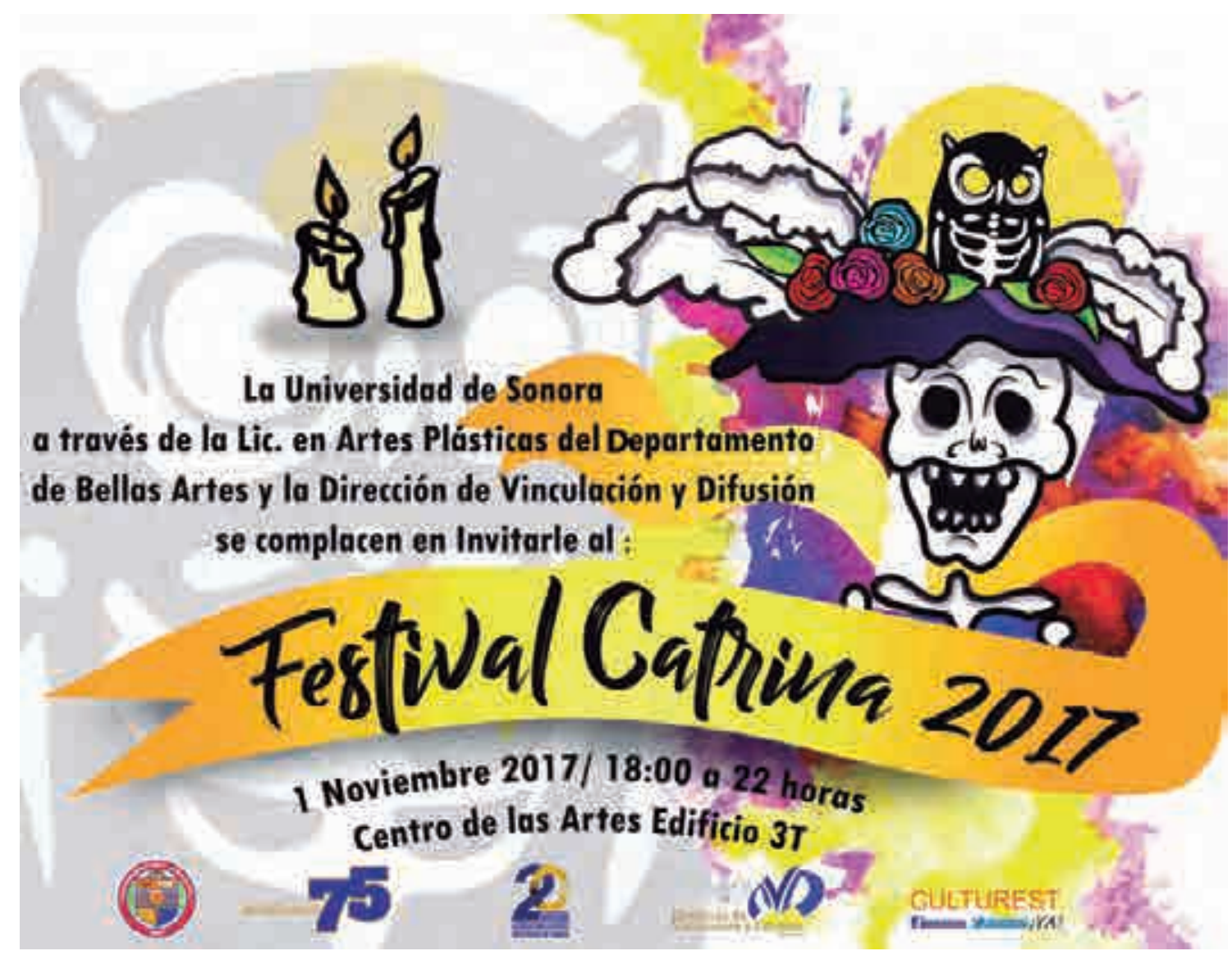

Festival Catrina 